\title{
Analisis Teacher Talk dan Student Talk dalam Bahasa Banjar pada Interaksi Pembelajaran Bahasa Inggris
}

\author{
${ }^{1}$ Vivi Aulia, ${ }^{2}$ Kuzairi \\ ${ }^{1,2}$ STKIP PGRI Banjarmasin, Indonesia
}

Email: ${ }^{1}$ viviauliavasa@yahoo.com, ${ }^{2}$ spirit.ahmadkzr@gmail.com

\begin{tabular}{l}
\hline Tersedia Online di \\
\hline http://www.jurnal.unublitar.ac.id/i \\
ndex.php/briliant
\end{tabular}

Sejarah Artikel

Diterima pada 22 Maret 2020

Disetujui pada 26 April 2020

Dipublikasikan pada 30 Mei 2020

Hal. 220-231

\section{Kata Kunci:}

Teacher talk; student talk; bahasa

Banjar; bahasa Inggris

\section{DOI:}

http://dx.doi.org/10.28926/briliant. v3i4.452

\begin{abstract}
Abstrak: Penelitian ini bertujuan untuk mengetahui kategori teacher talk dan student talk dalam bahasa Banjar pada interaksi pembelajaran bahasa Inggris berdasarkan Foreign Language Interaction Analysis (FLINT). Penelitian dilakukan pada satu kali pembelajaran bahasa Inggris kelas X SMAN 13 Banjarmasin. Penelitian ini berjenis deskriptif kualitatif dengan melakukan observasi dan perekaman interaksi guru dan siswa dalam bahasa Banjar selama proses pembelajaran bahasa Inggris sebagai teknik pengumpulan data. Data disajikan dalam bentuk deskripsi dialog interaksi antara guru dan siswa. Data penelitian dianalisis dengan mereduksi data, mengelompokkan teacher talk dan student talk yang nampak sesuai dengan kategori FLINT, serta menyimpulkan hasil kategori interaksi. Hasil penelitian ini menunjukkan bahwa kategori teacher talk menggunakan bahasa Banjar yang nampak adalah deals with feelings, asks questions,
\end{abstract} gives information, serta gives directions. Sementara itu, student talk yang terlihat adalah kategori student-initiated response saja. Penelitian ini menyimpulkan bahwa penggunaan bahasa ibu dalam interaksi pembelajaran bahasa Inggris dapat dilakukan berdasarkan kebutuhan siswa.

\section{PENDAHULUAN}

Pembelajaran sebagai suatu sistem terdiri dari satu kesatuan berbagai komponen yang saling bekerjasama, saling bersinergi, dan saling melengkapi untuk mencapai tujuan pembelajaran yang diharapkan. Soetopo dalam Helmiati (2013:5) menyebutkan bahwa pembelajaran merupakan suatu sistem yang terdiri dari banyak komponen yaitu siswa, guru, tujuan pembelajaran, materi pembelajaran, metode pembelajaran, sarana/alat belajar, evaluasi pembelajaran, dan lingkungan/konteks. Masing-masing komponen itu berdiri sendiri, namun ketika berproses dalam sebuah kegiatan pembelajaran, mereka saling bergantung untuk bersama-sama mencapai tujuan pembelajaran.

Pada aktivitas pembelajaran, interaksi antara komponen siswa dan komponen guru terjalin melalui bahasa kelas yang digunakan selama kegiatan pembelajaran berlangsung. Bahasa kelas menjadi alat komunikasi utama bagaimana interaksi terjadi antara guru dan siswa. Sebagaimana yang dinyatakan oleh Brown (2007:212) bahwa interaksi mengacu kepada sekumpulan pemikiran, ide, maupun ungkapan antara dua orang atau lebih untuk memberikan pemahaman satu sama lain. Teori komunikasi mempertegas pentingnya arti interaksi antar manusia dalam menggunakan bahasa sebagai media penyampai informasi. Oleh

220 BRILIANT: Jurnal Riset dan Konseptual

Volume 5 Nomor 2, Mei 2020 
karena itu, penggunaan bahasa menjadi penting untuk menghasilkan komunikasi yang efektif dalam sebuah interaksi pembelajaran antara guru dan siswa.

Interaksi pembelajaran yang dilakukan oleh guru dan siswa terwujud dalam bentuk teacher talk dan student talk. Teacher talk dan student talk mengacu kepada bahasa kelas yang digunakan oleh guru dan siswa selama proses pembelajaran berlangsung. Teacher talk merupakan bahasa lisan guru dalam interaksi, sedangkan student talk merupakan bahasa siswa. Pada proses ini, interaksi terjadi antara guru dan siswa dalam bentuk kegiatan bertanya, menjawab pertanyaan, menjelaskan, memberikan instruksi, serta kegiatan pembelajaran lainnya yang diucapkan secara lisan (Brown, 2007; Haradasht dan Aidinlou, 2016:1764; Puasa dkk, 2017:106-107).

Mengingat pentingnya keberadaan bahasa sebagai alat interaksi antara guru dan siswa dalam proses pembelajaran, maka guru perlu mengidentifikasi bahasa yang dipilih sebagai media penyampai informasi. Pilihan bahasa yang digunakan oleh guru turut menentukan berhasil tidaknya proses pembelajaran yang dilakukan, terutama pada mata pelajaran bahasa asing yang muatan materinya tidak menggunakan bahasa sehari-hari siswa. Contohnya adalah pembelajaran bahasa Inggris di Indonesia dimana siswa dilatih untuk mengenali bahasa asing selain bahasa ibu sebagai bahasa sehari-hari dan Bahasa Indonesia itu sendiri sebagai bahasa nasional.

Penggunaan bahasa daerah di Indonesia yang cukup mendominasi interaksi masyarakat sehari-hari menjadikan bahasa Inggris sebagai bahasa baru yang tidak bisa diadaptasi dengan cepat oleh siswa dalam proses pembelajarannya. Guru bahasa Inggris seringkali mengalami kendala dalam menyampaikan materi didalam kelas apabila dalam proses pembelajarannya tidak sebagian beralih menggunakan bahasa Indonesia untuk membantu siswa memahami materi. Demikian pula apabila dalam suatu pembelajaran bahasa Inggris, masih terdapat siswa yang belum memahami apa yang disampaikan oleh guru dengan menggunakan bahasa Indonesia. Guru menggunakan bahasa daerah sebagai bahasa alternatif untuk memperjelas makna yang ingin disampaikan.

Bozorgian dan Fallahpour (2015:70) melakukan penelitian mengenai penggunaan bahasa ibu atau bahasa daerah (first language) dalam pembelajaran bahasa Inggris sebagai bahasa asing. Temuan yang didapat menunjukkan bahwa penggunaan bahasa ibu memberikan kontribusi dalam hal mengatur kelas, memperjelas tujuan pembelajaran, memperjelas instruksi, membangun lingkungan belajar yang akrab, mempertegas makna dari apa yang dilakukan selama pembelajaran, serta membantu siswa mengurangi ketegangan dan kecemasan dalam belajar.

Debreli dan Oyman (2016:148-162) dan Shabir (2017:46-47) juga melakukan penelitian mengenai penggunaan bahasa ibu dalam pembelajaran bahasa Inggris sebagai bahasa asing. Hasilnya adalah siswa menggunakan bahasa ibu tidak hanya dalam aktivitas pembelajaran saja. Akan tetapi, mereka menggunakannya juga untuk diskusi selama pembelajaran berlangsung. Pada penelitian tersebut, frekuensi guru bahasa Inggris menggunakan bahasa ibu didominasi untuk menjelaskan arti vocabulary yang sulit serta menjelaskan grammar.

Selain tiga penelitian diatas, Alshehri (2917:20-33) juga meneliti hal yang mirip. Guru menggunakan bahasa ibu untuk beberapa tujuan dikelas, yaitu 
menjelaskan vocabulary dan membangun keakraban dengan siswa. Guru juga melaporkan bahwa mayoritas siswa menggunakan bahasa ibu untuk menerjemahkan vocabulary yang mereka tidak tahu serta untuk mengerjakan tugas-tugas dari guru. Keempat penelitian diatas menyimpulkan bahwa bahasa ibu digunakan dengan tujuan tertentu berdasarkan kondisi siswa dalam kelas yang diajar.

Dalam interaksi pembelajaran bahasa asing, terdapat salah satu sistem yang memberikan gambaran bagi guru dan siswa untuk menggunakan bahasa asing sebagai teacher talk dan student talk dalam proses pembelajaran. Sistem tersebut dikenal dengan istilah Foreign Language Interaction Analysis (FLINT) yang direkomendasikan oleh Moskowitz sebagai referensi bagaimana membangun interaksi pembelajaran bahasa asing antara guru dan siswa. Semua kategori FLINT tersebut dapat dilihat detil pada Tabel 1 berikut:

Tabel 1. Kategori pada Foreign Language Interaction Analysis (FLINT)

\begin{tabular}{|c|c|c|c|c|c|}
\hline \multirow{6}{*}{$\begin{array}{l}\text { Indirect } \\
\text { influence } \\
\text { of Teacher } \\
\text { Talk }\end{array}$} & 1 & $\begin{array}{l}\text { Deals with feelings } \\
\text { In a nonthreatening way, accepting, } \\
\text { discussing, referring to, or } \\
\text { communicating understanding of past, } \\
\text { present, or future feelings of students }\end{array}$ & \multirow{6}{*}{$\begin{array}{l}\text { Direct } \\
\text { influence } \\
\text { of Teacher } \\
\text { Talk }\end{array}$} & 5 & $\begin{array}{l}\text { Gives information. } \\
\text { Giving information, facts, } \\
\text { own opinion, or ideas: } \\
\text { lecturing or asking } \\
\text { rhetorical questions }\end{array}$ \\
\hline & 2 & $\begin{array}{l}\text { Praises or encourages: } \\
\text { Praising, complimenting, and telling } \\
\text { students why what they have said or } \\
\text { done is valued. Encouraging student to } \\
\text { continue, trying to give them } \\
\text { confidence, confirming that answers are } \\
\text { correct }\end{array}$ & & $\begin{array}{l}5 \\
a\end{array}$ & $\begin{array}{l}\text { Corrects without } \\
\text { rejection. } \\
\text { Telling students who have } \\
\text { made a mistake the } \\
\text { correct response without } \\
\text { using words or } \\
\text { intonations which } \\
\text { communicate criticism. }\end{array}$ \\
\hline & $\begin{array}{l}2 \\
\mathrm{a}\end{array}$ & $\begin{array}{l}\text { Jokes } \\
\text { Intentional joking, kidding, making } \\
\text { puns, attempting to be humorous, } \\
\text { providing the joking is not at anyone's } \\
\text { expense. Unintentional humor is not } \\
\text { included in this category. }\end{array}$ & & 6 & $\begin{array}{l}\text { Gives directions. } \\
\text { Giving directions, } \\
\text { requests, or commands } \\
\text { that students are expected } \\
\text { to follow; directing } \\
\text { various drills; facilitating } \\
\text { whole-class and small- } \\
\text { group activity }\end{array}$ \\
\hline & 3 & $\begin{array}{l}\text { Uses ideas of students. } \\
\text { Clarifying, using, interpreting, } \\
\text { summarizing the ideas of students. The } \\
\text { ideas must be rephrased by the teacher } \\
\text { but still be recognized is being student } \\
\text { contributions. }\end{array}$ & & 7 & $\begin{array}{l}\text { Criticizes student } \\
\text { behavior. Rejecting the } \\
\text { behavior of students; } \\
\text { trying to change the non- } \\
\text { acceptable behavior; } \\
\text { communicating anger, } \\
\text { displeasure, annoyance, } \\
\text { dissatisfaction with what } \\
\text { students are doing }\end{array}$ \\
\hline & $\begin{array}{l}3 \\
\mathrm{a}\end{array}$ & $\begin{array}{l}\text { Repeats student response verbatim. } \\
\text { Repeating the exact words of students } \\
\text { after they participate }\end{array}$ & & 7 & $\begin{array}{l}\text { Criticizes student } \\
\text { response. } \\
\text { Telling the student his or } \\
\text { her response is not correct } \\
\text { or acceptable and }\end{array}$ \\
\hline & 4 & $\begin{array}{l}\text { Asks questions. } \\
\text { Asking questions to which the answer is } \\
\text { anticipated. Rhetorical questions are not } \\
\text { included in this category. }\end{array}$ & & $\boldsymbol{a}$ & $\begin{array}{l}\text { communicating criticism, } \\
\text { displeasure, annoyance, } \\
\text { rejection by words or } \\
\text { intonation }\end{array}$ \\
\hline
\end{tabular}




\begin{tabular}{|l|l|}
\hline \multirow{5}{*}{ Student } & $\begin{array}{l}\text { 8. Student response, specific. Responding to the teacher within a specific and limited } \\
\text { range of available or previously practiced answers. Reading aloud, dictation, drills } \\
\text { 8a. Student response, choral. Choral response by total class or part of class } \\
\text { 9. Student response, open-ended or student-initiated. Responding to the teacher with } \\
\text { students' own ideas, opinions, reactions, feelings. Giving one from among many possible } \\
\text { answers that have been previously practiced but from which students must now make a } \\
\text { selection. Initiating the participation }\end{array}$ \\
\hline \multirow{5}{*}{ 10. Silence. Pauses in the interaction. Periods of quiet during which there is no verbal } \\
interaction \\
$\begin{array}{l}\text { 10a. Silence-audiovisual. Silence in the interaction during which a piece of audiovisual } \\
\text { equipment,e.g. a tape recorder, filmstrip projector, record player, etc., is being used to } \\
\text { communicate } \\
\text { 11. Confusion, work-oriented. More than one person at a time talking, so the interaction } \\
\text { cannot be recorded. Students calling out excitedly, eager to participate or respond, } \\
\text { concerned with the task at hand } \\
\text { 11a. Confusion, non-work-oriented. More than one person at a time talking so the } \\
\text { interaction cannot be recorded. Students out of order, not behaving as the teacher wishes, } \\
\text { not concerned with the task at hand } \\
\text { 12. Laughter. Laughing and giggling by the class, individuals, and/or the teacher } \\
\text { 13. Uses the native language. Use of the native language by the teacher or the students. } \\
\text { This category is always combined with one of the categories from } 1 \text { to } 9 . \\
\text { 14. Nonverbal. Gestures or facial expressions by the teacher or the student that } \\
\text { communicate without the use of words. This category is always combined with one of the } \\
\text { categories of teacher or student behavior. }\end{array}$ \\
\hline
\end{tabular}

Dikutip dari: Brown (2007:217)

Tabel 1 diatas menunjukkan bahwa penggunaan bahasa ibu berada pada kategori nomor 13 dimana guru dan siswa dapat menggunakannya dalam interaksi pembelajaran bahasa Inggris dengan mengacu pada semua kategori teacher talk dan student talk nomor 1 sampai dengan nomor 9. Dengan demikian, guru dan siswa dapat menggunakan bahasa ibu untuk melakukan aktivitas pembelajaran bahasa asing yang terwujud dalam teacher talk dan student talk sesuai dengan kebutuhan.

Di kota Banjarmasin, Kalimantan Selatan, interaksi yang terjadi antara guru dan siswa di sekolah masih didominasi oleh bahasa Banjar. Sebagai bahasa daerah utama yang digunakan dalam komunikasi sehari-hari masyarakat di lingkungan Kalimantan Selatan, frekuensi penggunaan bahasa Banjar masih sangat mendominasi dalam interaksi pembelajaran bahasa Inggris di kelas. Tidak hanya berfungsi sebagai komunikasi formal dan nonformal antara guru dan siswa, bahasa Banjar masih difungsikan sebagai teacher talk dan student talk dalam kondisi tertentu pada pembelajaran bahasa Inggris.

Berdasarkan paparan diatas, penelitian ini bertujuan untuk mengetahui kategori teacher talk dan student talk apa saja yang terlihat dalam bahasa Banjar pada interaksi pembelajaran bahasa Inggris di salah satu SMA di Kota Banjarmasin berdasarkan sistem FLINT. Urgensi dilakukannya penelitian ini berdasarkan pada pernyataan Puasa dkk (2017:107) bahwa keberhasilan maupun kegagalan sebuah aktivitas pembelajaran turut ditentukan oleh bahasa yang digunakan oleh guru. Frekuensi teacher talk yang digunakan oleh guru dalam konteks yang kurang sesuai dengan kondisi siswa akan memberikan suasana belajar yang membosankan karena siswa hanya pasif mendengar apa yang guru bicarakan atau bahkan mengabaikan apa yang disampaikan oleh guru.

Selain itu, ketidaktepatan tingkat bahasa yang digunakan guru akan menimbulkan problem lainnya bagi siswa dalam memahami materi pembelajaran bahasa Inggris. Harmer (1998:3) menegaskan bahwa teacher talk merupakan 
kunci untuk melibatkan siswa dalam pembelajaran. Guru dituntut memiliki kepekaan akan kondisi siswa yang diajarnya. Mereka harus menyesuaikan diri dengan level bahasa yang digunakan. Dalam konteks pembelajaran bahasa Inggris, penggunaan bahasa ibu memungkinkan digunakan dalam proses interaksi pembelajaran berdasarkan kebutuhan siswa. Oleh karena itu, penelitian ini diharapkan dapat menjadi referensi penggunaan teacher talk dan student talk berdasarkan kategori FLINT sebagai salah satu acuan interaksi pembelajaran bahasa asing.

\section{METODE}

Penelitian ini berjenis deskriptif dengan pendekatan kualitatif yang bertujuan untuk mengetahui kategori teacher talk dan student talk apa saja yang terlihat dalam bahasa Banjar pada pembelajaran bahasa Inggris berdasarkan sistem FLINT. Lokasi penelitian ini bertempat di SMAN 13 Banjarmasin dimana penelitian dilakukan pada mata pelajaran bahasa Inggris yang dilaksanakan di salah satu kelas $X$. Teknik pengumpulan data dilakukan dengan cara mengamati interaksi pembelajaran bahasa Inggris selama satu kali pertemuan dan merekam teacher talk dan student talk dalam bahasa Banjar yang terlihat selama proses interaksi.

Instrumen penelitian ini menggunakan lembar observasi dan perekam suara (voice recorder). Lembar observasi digunakan untuk mencatat hasil penting yang nampak pada interaksi pembelajaran bahasa Inggris antara guru dan siswa ketika menggunakan bahasa Banjar secara verbal dengan mengacu kriteria FLINT pada Tabel 1. Sementara itu, perekam suara (voice recorder) digunakan untuk merekam dan mendokumentasikan teacher talk dan student talk dalam bahasa Banjar selama kegiatan pembelajaran bahasa Inggris berlangsung. Tujuan perekaman ini adalah mendapatkan transkrip lengkap teacher talk dan student talk untuk mendukung data hasil observasi.

Semua data yang didapat dianalisis menggunakan tiga langkah analisis data yang dikemukakan oleh Miles and Huberman dalam Sugiyono (2014:91-99) yaitu reduksi data, penyajian data setelah direduksi, dan verifikasi data atau penarikan kesimpulan. Pada reduksi data, peneliti menganalisis hasil observasi serta menganalisis transkrip teacher talk dan student talk dalam bahasa Banjar dan mengkategorikan setiap data tersebut dengan kriteria pada Tabel 1. Setelah melakukan reduksi data, peneliti menyajikan data dengan mendeskripsikan kategori FLINT apa saja yang terlihat pada teacher talk dan student talk dalam bahasa Banjar di kelas yang diteliti. Langkah terakhir analisis data adalah penarikan kesimpulan. Pada tahap ini, peneliti menyimpulkan hasil analisis teacher talk dan student talk yang nampak dalam bahasa Banjar pada interaksi pembelajaran bahasa Inggris berdasarkan kategori pada sistem FLINT dengan pembahasan berdasarkan literatur yang relevan.

\section{HASIL}

Penggunaan bahasa Banjar dalam bentuk teacher talk dan student talk pada interaksi pembelajaran di SMAN 13 Banjarmasin disajikan dengan ujaran yang digarisbawahi sebagai berikut: 


\section{Data 1}

Guru membagi kelas kedalam kelompok-kelompok.

Guru : So, yang kelompok. Satu kumpul, dua kumpul, tiga kumpul, empat kumpul! (nomor

1 berkumpul, nomor 2 berkumpul, nomor 3 berkumpul, nomor empat berkumpul)

Siswa A : Satu mana satu ......(memindah kursi untuk mencari anggota)

Guru meminta siswa untuk saling berpindah mengubah tempat duduk dengan tidak menutup jalan

Siswa B : Ai aku... buhan ikam nah! (bukan aku, tapi kelompok kalian)

Guru : Attention please! (guru memberikan instruksi kepada semua siswa untuk focus). Jadi ini kan sudah dibagi kelompoknya. Hari ini kita main game berkelompok. Game nya tentang whisper. Taulah whisper?(apakah kalian tahu whisper?)

Guru menjelaskan game yang akan dimainkan

Guru : Jadi ini kan kena bejejer nih. Disini aja bejejernya. Kalo disana kada bisa (nanti kalian berdiri berjejer disini. Kalau berjejer disana tidak bisa)

Berdasarkan data 1 diatas, teacher talk yang nampak ketika menggunakan bahasa Banjar berfungsi untuk gives directions atau memberikan arahan. Guru memberikan arahan kepada siswa untuk membentuk kelompok Selain itu, juga terdapat gives information yang ditandai dengan penggunaan rhetorical question yaitu taulah whisper? (apakah whisper itu). Adapun student talk pada data 1 ini terdapat respons siswa yang berbentuk student-initiated response dimana siswa secara individu mengomentari instruksi dari guru untuk membuat kelompok.

\section{Data 2}

Guru melanjutkan penjelasan mengeni durasi waktu permainan yang akan dilakukan

Guru : Waktunya 20 detik!

Beberapa siswa berbisik-bisik menanggapi penjelasan guru

Siswa A : Jakanya 25 detik (seandainya 25 detik)

Guru mendengar siswa yang berbisik-bisik dan membuat kesepakatan dengan siswa mengenai waktu permainan

Guru : Sepakatlah dulu 20 detik?(apakah sepakat kalau 20 detik?)

Siswa masih berbisik-bisik antar temannya

Siswa B : Setengah jam habis waktu. 30 detik aja gin. 30 gin. Biasanya guru lain $\underline{30}$ detik jua. (Setengah jam habis waktunya. 30 detik saja. Biasanya guru lain 30 detik juga)

Pada data 2 diatas, teacher talk dalam bahasa Banjar merupakan kategori gives information dimana guru menggunakan rhetorical question untuk mengajak siswa bersepakat mengenai durasi waktu permainan. Sementara itu, student talk yang terdapat pada data 2 diatas termasuk kategori student-initiated response dimana siswa melakukan tawar menawar terhadap instruksi guru yang seharusnya tidak dilakukan.

\section{Data 3}

Ketika permainan dimulai, situasi kelas sangat ramai dengan siswa membuat barisan berdasarkan instruksi guru

Guru $\quad$ Handak disini ajakah atau bikin jalan disana? (apakah mau disini saja atau membuat jalan disana?)

Guru bertanya kepada semua siswa dengan menunjuk ke lorong antar kursi siswa

Siswa A : Jalan disana aja Bu.

Siswa yang lain menanggapi dengan saling bersahutan

Siswa B $\quad$ : Kada nih. Kawa ae. Muat ae. (jalannya cukup muat untuk dilewati)

Siswa C : Bebaris ai. Kayapa? Aku dimana nih.....(bagaimana barisnya?)

Siswa D : Nah kemana pulang bejalanan (kemana lagi kita berjalan)

Riuh terdengar mereka saling sahut menyahut dalam membuat barisan untuk permainan 
Data 3 diatas menunjukkan teacher talk yang termasuk kategori asks questions dimana guru bertanya kepada siswa mengenai pilihan area dikelas untuk melakukan permainan. Selain itu, student talk diatas menunjukkan bahwa bahasa Banjar yang digunakan oleh lebih dari satu siswa berfungsi sebagai studentinitiated response dimana siswa memberikan respons dan ujaran bermacammacam mengenai permainan yang akan dilakukan.

\section{Data 4}

Siswa bergantian memainkan permainan whisper

Guru : Kelompok yang kada main siapa? Siapa yang mau jadi time keeper? (kelompok siapa yang tidak sedang bermain?

Seorang : Time keeper. Yang kada main. (yang sedang tidak bermain)

siswa

Guru : Yang lain jaga pemainnya, jangan lawas-lawas, membisikinya 30 detik (jangan lamalama). Yang lain tolong tertib, kecilkan volume suara.

Suasana kelas sangat riuh. Siswa saling bersahutan terlibat dalam permainan

Siswa A : Bahasanya nih formal kah? (apakah bahasanya formal?)

Siswa $B \quad$ : Kada. Kada formal (Tidak. Tidakformal)

Siswa $C \quad$ : Oooo...nyaringnya, nyaringnya (keras sekali suaranya)

Siswa $D \quad$ : Kadangaran (suaranya terdengar)

Satu kelompok selesai bermain game. Guru memanggil kelompok berikutnya untuk memainkan permainan.

Guru : Sudah sudah, yang kedua lagi, beacak dulu susunannya (diacak dulu susunannya)

Situasi kelas sangat ramai ketika kelompok berikutnya akan bersiap melakukan permainan

Guru : Ini yang diacak muka lawan belakang aja (depan dan belakang saja)

Seorang : Kada boleh ganti kah? Oke ke pinggir (apakah tidak bisa diganti?)

siswa

Data 4 diatas menunjukkan bahwa teacher talk yang terlihat masih berfungsi sebagai asks questions dan gives directions dalam hal mengontrol pelaksanaan game yang dilaksanakan siswa, sedangkan student talk dalam bahasa Banjar memperlihatkan student-initiated response dimana beberapa siswa saling mengingatkan teman-temannya untuk menurunkan volume suara sesuai arahan guru.

\section{Data 5}

Siswa mengingatkan guru bahwa jam pelajaran bahasa Inggris sudah berakhir untuk sesi pertama. Seorang siswa : Aaa..sudah lewat 3 menit. Kada papa kada papa (tidak apa-apa). Lanjut lanjut.... Guru : Istirahat aja gin dulu (istirahat saja dulu). Habis istirahat kita lanjut lagi. Semua siswa keluar kelas untuk istirahat. Ketika waktu istirahat usai, siswa kembali masuk kelas dan melanjutkan kegiatan pembelajaran bahasa Inggris sesi kedua. Guru meneruskan pembahasan materi di papan tulis

Guru

Coba semuanya fokus dulu ke papan tulis. Ini kan jenis pekerjaan. Jadi semuanya punya cita-cita lo? (semuanya pasti punya cita-cita). Jadi kayapa caranya supaya si cita-cita tadi tercapai?(bagaimana caranya agar cita-cita kalian tercapai?)

Siswa A

Guru

Siswa B Niat Bu

Oke. Niat, doa, ikhtiar, usaha. Selain itu?

Guru

Dukungan orang tua

Pasti mencari job opportunitiesnya dulu lo? (mencari lowongan pekerjaan dulu kan) Misalnya handak (ingin) bekerja jadi banker, pasti mencari lowongan pekerjaannya dulu lo? (mencari lowongan pekerjaan dulu kan). Nah pas sudah dapat lowongannya trus diapai lagi?(setelah itu lowongannya diapakan?)

Berdasarkan data 5 diatas, terdapat student talk yaitu kategori student-iniated response dimana siswa mengingatkan waktu pembelajaran sudah habis. Pada interaksi ini juga terdapat teacher talk yang berfungsi sebagai deals with feelings yang mana guru memberikan jeda waktu istirahat kepada siswa sebelum memulai pembelajaran bahasa Inggris kembali. Selain itu, guru asks question kepada siswa

226 BRILIANT: Jurnal Riset dan Konseptual Volume 5 Nomor 2, Mei 2020 
dengan memberikan pertanyaan mengenai apa yang harus dilakukan agar cita-cita tercapai dan dijawab siswa dengan jawaban variatif.

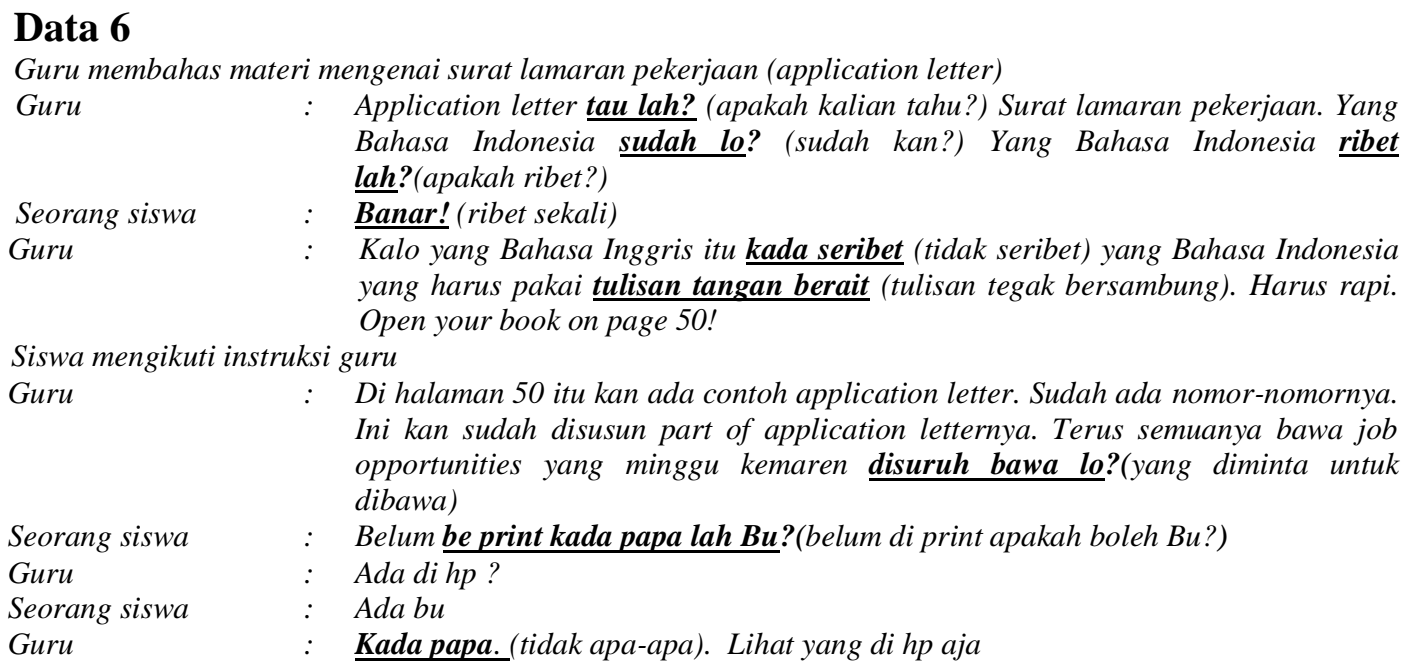

Data 6 diatas menunjukkan bahwa teacher talk dalam bahasa Banjar berfungsi untuk gives informations pada rhetorical questions yang diberikan kepada siswa, seperti: taulah?, sudah lo?, dan ribetlah? . Guru memberikan informasi mengenai materi yang akan dibahas dikelas. Selain itu juga terdapat student talk yaitu student-initiated response dimana siswa menjawab pertanyaan guru dengan jawaban banar! dengan maksud membenarkan pernyataan dari guru tersebut. Diakhir situasi ini, guru memberikan arahan (gives direction) kepada siswa untuk menggunakan ponsel bagi yang tidak membawa iklan lowongan pekerjaan yang ditugaskan.

\section{PEMBAHASAN}

Interaksi antara guru dan siswa menjadi komponen yang sangat penting dalam mendukung keberhasilan sebuah proses pembelajaran. Interaksi tersebut mengindikasikan adanya situasi yang komunikatif antara guru dan siswa dengan menggunakan bahasa tertentu untuk mencapai tujuan pembelajaran. Pemilihan bahasa menjadi faktor krusial dalam interaksi ini karena tersampaikannya informasi secara dua arah antara guru dan siswa ditentukan oleh bahasa yang dipilih. Dalam konteks pembelajaran bahasa Inggris sebagai bahasa asing di Indonesia, penggunaan bahasa Inggris maupun bahasa Indonesia sebagai bahasa pengantar harus mempertimbangkan kebutuhan, kondisi, dan karakteristik siswa. Demikian pula bila dalam sebuah kondisi tertentu, guru menggunakan bahasa ibu sebagai bahasa pengantar dalam pembelajaran bahasa Inggris seperti pada penelitian ini.

Hasil penelitian ini menunjukkan bahwa interaksi pembelajaran bahasa Inggris yang tercermin dalam ujaran yang diucapkan guru (teacher talk) dan ujaran yang diucapkan siswa (student talk) secara verbal di salah satu kelas $\mathrm{X}$ SMA Negeri 13 Banjarmasin didominasi oleh bahasa ibu dan bahasa Indonesia sebagai bahasa pengantar. Dalam hal ini, bahasa ibu yang digunakan oleh guru dan siswa adalah bahasa Banjar. Minim sekali terlihat adanya penggunaan bahasa Inggris itu sendiri sebagai alat interaksi antara guru dan siswa. Karakter siswa yang heterogen serta memiliki latar belakang penguasaan bahasa Inggris yang 
bervariasi menyebabkan penyampaian informasi dalam pembelajaran memerlukan peran bahasa ibu untuk memudahkan mereka memahaminya.

Dalam konteks penelitian ini, penggunaan bahasa Banjar pada pembelajaran bahasa Inggris terwujud dalam interaksi antara guru dan siswa ketika mereka berada dalam aktivitas belajar dikelas. Berdasarkan kategori interaksi pembelajaran bahasa asing yang terdapat dalam sistem FLINT, teacher talk yang mucul dalam bahasa Banjar pada penelitian ini termasuk dalam empat kategori yaitu: (1) gives directions, (2) gives informations, (3) asks questions, serta (4) deals with feelings. Sementara itu, student talk yang nampak pada interaksi pembelajaran bahasa Inggris di sekolah ini termasuk dalam kategori student-initiated response saja.

Kategori pertama teacher talk yang terlihat dalam bahasa Banjar pada pembelajaran bahasa Inggris di SMAN 13 Banjarmasin adalah gives directions. Kategori ini mengacu pada aktivitas dimana guru memberikan arahan, memberikan instruksi kepada siswa untuk melakukan sesuatu, serta memfasilitasi kegiatan pembelajaran seperti berkelompok maupun diskusi. Contoh teacher talk yang mengacu pada kegiatan ini yaitu "satu kumpul, dua kumpul, tiga kumpul, empat kumpul pada data 1 dimana guru mengarahkan siswa untuk saling berkumpul dengan kelompoknya. Contoh lain ketika guru mengontrol permainan yang dilakukan siswa pada data 4 dengan kalimat jangan lawas-lawas dan beacak dulu susunannya. Maksud kalimat ini adalah siswa tidak berlama-lama membisik temannya serta meminta siswa mengacak susunan kalimat dalam permainan. Guru harus memberikan arahan (giving direction) yang jelas untuk memfasilitasi informasi mengenai apa yang harus dilakukan siswa dalam aktivitas pembelajaran secara sistematis (Sofyan dan Mahmud, 2014:56).

Kategori teacher talk kedua dalam bahasa Banjar yang terlihat pada penelitian ini adalah gives informations. Kategori ini merupakan ujaran guru dalam memberikan informasi berupa fakta, opini, atau ide-ide berupa penjelasan maupun pertanyaan retorik kepada siswa. Pada penelitian ini, giving information yang diucapkan oleh guru didominasi oleh pertanyaan retorik (rhetorical question) seperti: taulah...?, pahamlah...?, sepakatlah....?, dan sejenisnya berupa semacam tag question yang sebelumnya didahului oleh penjelasan dan penegasan guru mengenai aktivitas maupun materi yang dipelajari. Secara umum, tag question seperti ini berfungsi untuk meminta siswa memperhatikan ide atau poin tertentu dari pernyataan atau kalimat yang disampaikan guru sebelumnya (Alotaibi dan Alotaibi, 2015:1).

Teacher talk berikutnya dalam penelitian ini adalah asks question dimana guru memberikan pertanyaan yang memerlukan jawaban dari siswa. Contoh pertanyaan guru menggunakan bahasa Banjar yaitu pada data 3 ketika guru bertanya handak disini ajakah....?. Pada situasi ini, guru menanyakan posisi permainan yang akan dilakukan di kelas dan dijawab pasti oleh siswa yaitu jalan disana aja Bu!. Dalam hal ini, konteks pertanyaan guru hanya sekedar konfirmasi mengenai teknis pelaksanaan permainan. Seperti halnya pada data 4, guru bertanya kepada siswa kelompok yang kada main siapa? untuk sekedar mencari tahu kelompok lain yang sedang tidak memainkan permainan.

Al-Zahrani dan Al-Bargi (2017:137-138) menegaskan bahwa aktivitas bertanya yang dilakukan guru diklasifikasikan dalam dua tipe yaitu pertanyaan yang berorientasi ketepatan dan pertanyaan yang berorientasi kelancaran. Pada 
kedua tipe ini, peran guru dan siswa berbeda. Guru berperan memberikan pertanyaan, sedangkan siswa terbatas hanya memberikan jawaban secara singkat. Pada pertanyaan yang berorientasi ketepatan, teacher talk lebih mendominasi aktivitas kelas dan pertanyaan guru diaplikasikan dalam bentuk kegiatan siswa. Sementara, pertanyaan yang berorientasi pada kelancaran mengutamakan porsi siswa untuk lebih banyak menjawab dan mengekspresikan idenya. Porsi teacher talk lebih sedikit dan keaktifan siswa menjawab lebih banyak. Pada penelitian ini, asks question yang dilakukan guru pada data 4 diatas termasuk tipe pertanyaan yang berorientasi pada ketepatan. Sementara itu, pertanyaan yang berorientasi pada kelancaran tampak pada data 5 dimana guru bertanya bagaimana caranya agar cita-cita tercapai melalui pertanyaan kayapa caranya supaya si cita-cita tadi tercapai? yang dijawab siswa dengan jawaban variatif. Jawaban bervariasi tersebut menunjukkan bahwa siswa memiliki ide bermacam-macam untuk mengungkapkan pendapatnya sesuai pertanyaan guru.

Kategori teacher talk yang terakhir dalam bahasa Banjar pada penelitian ini adalah deals with feelings. Kategori ini mengacu pada ujaran guru untuk menerima dan memahami kondisi siswa. Data 5 penelitian ini memperlihatkan bahwa guru meminta siswa untuk beristirahat dulu sebelum memulai kembali pembelajaran dengan kalimat istirahat aja gin dulu. Pada situasi ini, guru memahami bahwa siswa memerlukan jeda waktu untuk mengistirahatkan otak sejenak agar dapat fokus kembali pada aktivitas kelas. Guru yang memahami kondisi semacam ini akan menimbulkan rasa nyaman bagi siswa untuk berinteraksi kembali dengan kegiatan kelas (Sofyan dan Mahmud, 2014:46-47).

Selain teacher talk dalam bahasa Banjar yang diucapkan guru, student talk yang diucapkan siswa juga terlihat pada penelitian ini. Berdasarkan sistem FLINT, terdapat satu kategori student talk yang nampak pada pembelajaran bahasa Inggris di SMAN 13 Banjarmasin pada interaksi pembelajaran yang diamati yaitu kategori student-initiated response. Respons ini diucapkan siswa sebagai bagian dari partisipasi dalam aktivitas kelas. Bentuk dari student-initiated response adalah situasi dimana siswa secara individu berpartisipasi memberikan respons terhadap ujaran guru mengenai aktivitas yang dilakukan. Seperti contoh pada data 3, siswa menanggapi guru dengan berbagai ujaran, seperti: seorang siswa mengatakan kada nih, kawa ae yang memiliki makna jalannya cukup muat untuk dilewati, kemudian siswa lainnya berujar bebaris ai yang berarti mengajak temannya untuk berbaris. Hampir semua data student talk yang diamati dan direkam pada penelitian ini menunjukkan kategori student-initiated response.

Contoh lain terlihat pada data 4 dimana siswa secara individu memberikan respons ketika guru meminta semua siswa untuk tertib dengan menurunkan volume suara. Kemudian, siswa menanggapi dengan meminta teman-temannya untuk menurunkan volume suara dengan mengatakan nyaringnya, nyaringnya. Pengulangan kata ini menunjukkan peringatan kepada temannya agar mengecilkan volume suara. Jenis student-initiated response seperti ini merupakan respons yang diberikan siswa sebagai pemahaman akan instruksi yang diberikan guru. Initiation merupakan salah satu stimulus pertanyaan ditujukan kepada siswa yang sifatnya dapat berupa "pancingan" dari topik yang dibicarakan maupun berupa petunjuk, instruksi, serta informasi. Tujuannya adalah mendorong semua siswa memberikan partisipasi dalam interaksi pembelajaran yang sedang berlangsung (Tuan dan Nhu, 2010:31-32; Ul Huq dan Amir, 2015:61). 
Berdasarkan pembahasan diatas, teacher talk dan student talk dalam sebuah pembelajaran memiliki peran vital dalam menciptakan interaksi dan komunikasi dua arah yang efektif dalam proses pembelajaran. Penggunaan bahasa ibu sebagai bahasa pengantar dalam pembelajaran bahasa Inggris harus didasarkan pada pertimbangan berdasarkan kondisi kelas yang ada.

\section{KESIMPULAN}

Penelitian ini menyimpulkan bahwa penggunaan teacher talk dan student talk bahasa Banjar dalam pembelajaran bahasa Inggris kelas X SMAN 13 Banjarmasin termasuk dalam kategori yang terdapat pada sistem FLINT. Teacher talk yang nampak dalam bahasa Banjar termasuk dalam empat kategori berdasarkan FLINT yaitu: (1) gives directions, (2) gives informations, (3) asks questions, serta (4) deals with feelings. Sementara itu, student talk yang terlihat pada interaksi pembelajaran bahasa Inggris di sekolah ini termasuk dalam kategori student-initiated response saja. Kategori student talk lainnya masih belum terlihat pada pembelajaran bahasa Inggris pada kelas yang diamati.

\section{SARAN}

Guru bahasa Inggris perlu mengidentifikasi secara jelas bagaimana dan kapan menggunakan bahasa ibu pada kelas yang diajarnya. Dengan demikian, penggunaan bahasa ibu akan lebih tepat dengan menguraikan dimana bahasa ibu dapat digunakan berdasarkan kondisi siswa. Dalam hal ini, pihak sekolah perlu menyusun petunjuk penggunaan bahasa ibu dalam pembelajaran, sehingga guru tidak merasa bersalah ketika bahasa lain selain bahasa Inggris digunakan dikelas.

\section{DAFTAR RUJUKAN}

Alotaibi, A.M., dan Alotaibi, M.A. 2015. Syntactic Proficiency of Kuwaiti EFL Learners: A Study of Tag Questions. English Language Teaching, 8(8): $1-9$

Alshehri, E. 2017. Using Learner's First Language in EFL Classrooms. IAFOR Journal of Language Learning. 3(1):20-33

Al-Zahrani, M.Y., dan Al-Bargi, A. 2017. The Impact of Teacher Questioning on Creating Interaction in EFL: A Discourse Analysis. English Language Teaching, 10(6): 135-150

Bozorgian, H., dan Fallahpour, S. 2015. Teachers' and Students' Amount and Purpose of L1 Use: English as Foreign Language (EFL) Classrooms in Iran. Iranian Journal of Language Teaching Research, 3(2): 67-81

Brown, H.D. 2007. Teaching by Principles. An Interactive Approach to Language Pedagogy. New York: Pearson Education, Inc.

Debreli, E., dan Oyman, N. 2016. Students' Preferences on the Use of Mother Tongue in English as a Foreign Language Classroom: Is it the Time to Re-examine English-only Policies?. English Language Teaching, 9(1):148-162

Haradasht, M.A., dan Aidinlou, N.A. 2016. A Case Study on EFL Classroom Discourse. International Journal of Humanities and Cultural Studies. 2(Special Issue):1762-1770

Harmer, J. 1998. How to Teach English. Essex: Longman. 
Helmiati. 2013. Micro Teaching. Melatih Keterampilan Dasar Mengajar. Yogyakarta: CV. Aswaja Pressindo

Puasa, K., Asrifan, A., dan Chen, Y. 2017. Classroom Talk in Bilingual Class Interaction. Research in Pedagogy, 7(1):106-121

Shabir, M. 2017. Student-Teachers' Beliefs on the Use of L1 in EFL Classroom: A Global Perspective. English Language Teaching, 10(4): 45-52

Sofyan, R.R., dan Mahmud, M. 2014. Teacher Talk in Classroom Interaction: A Study at an English Department in Indonesia. ELT Worldwide, 1(1): 4558

Sugiyono. 2014. Memahami Penelitian Kualitatif. Bandung: CV.Alfabeta

Tuan, L.T., dan Nhu, N.T.K. 2010. Theoretical Review on Oral Interaction in EFL Classrooms. Studies in Literature and Language, 1(4): 29-48

Ul-Huq, R., dan Amir, A. 2015. When the Tokens Talk: IRF and the Position of Acknowledgement Tokens in Teacher-Student Talk-In Interaction. Novitas-ROYAL (Research on Youth and Language), 9(1): 60-76 